\title{
Lactancia: la firma de los mamíferos
}

\author{
Breastfeeding: the signing of mammals
}

\author{
Dulce María del Carmen Delgadillo Álvarez ${ }^{\mathrm{a},{ }^{*}}$ \\ ${ }^{a}$ Centro de Investigación y de Estudios Avanzados del Instituto Politécnico Nacional (IPN), México
}

\section{RESUMEN}

Los mamíferos son animales vertebrados cuya principal característica es la lactancia, período en el que las hembras alimentan a sus crías con la leche de sus mamas y con ello las protegen y contribuyen a asegurar su supervivencia. La lactancia se inicia inmediatamente después del nacimiento de las crías y se extiende hasta que estas pueden conseguir su alimento solas; ese momento coincide con la disminución en la expresión del gen que codifica para la enzima lactasa que es la que rompe a la lactosa de la leche permitiendo con ello el directo aprovechamiento de la glucosa en el metabolismo del individuo. Sin embargo, en el caso del hombre, la expresión de la lactasa se prolonga durante gran parte de su vida, lo que le permite seguir consumiendo leche, aunque cabe aclarar que de especies diferentes a la suya, y es que, al lograr domesticar al ganado, el descubrimiento del proceso de ordeña significó un gran avance para el ser humano, porque de esa manera no tenía que sacrificar al animal para obtener un alimento altamente nutritivo. En este artículo precisamente se tiene como objetivo revisar algunos aspectos de la lactancia de las diferentes subclases de mamíferos, la importancia de la leche misma y cómo el hombre ha sido capaz de obtenerla de otras especies de mamíferos para su consumo propio.

Palabras clave: Mamífero, lactancia, leche, glándula mamaria.

\begin{abstract}
Mammals are vertebrate animals whose main feature is breastfeeding the period in which females feed their young with milk from their mammary glands and thus protect them and help to ensure their survival. Breastfeeding starts immediately after birth of the offspring and extends until they can get their food alone; the time coincides with the decrease in the expression of the gene coding for the enzyme lactase that is which breaks lactose from milk thus allowing direct use of glucose metabolism of the individual. However, in the case of man, the expression of lactase extends for much of his life. This allows him to continue consuming milk, although it should be noted that that milk comes from different species to his and it is that, to tame cattle the discovery of the milking process meant a breakthrough for the human being, because that way he does not have to sacrifice the animal to obtain a highly nutritious food. This article aims to revise some aspects of the breastfeeding of the different subclasses of mammals, the importance of the milk and how the man has been able to get it from other species of mammals for their own consumption.
\end{abstract}

Keywords: Mammal, breastfeeding, milk, mammary gland.

Historial del artículo:

Recibido, 22 de febrero de 2016; aceptado, 8 de marzo de 2016; disponible en línea, 30 de marzo de 2016

* Licenciada en Biología, Maestra en Ciencias en el área de Patología Experimental, Doctora en Ciencias en Biomedicina Molecular por el Centro de Ciencia Aplicada y Tecnología Avanzada del Instituto Politécnico Nacional.

Correo:dulmadelca@hotmail.com

Este es un artículo de acceso abierto, licencia CC BY (https://creativecommons.org/licenses/by/4.0/) 


\section{INTRODUCCIÓN}

La palabra mamífero define la clase de animales vertebrados (figura 1) de temperatura constante, cuyo embrión, provisto de amnios y alantoides, se desarrolla casi siempre dentro del cuerpo materno. Este grupo de organismos presenta características anatómicas y fisiológicas exclusivas como la presencia de pelo en alguna etapa de su desarrollo aunque la mayoría lo conserva durante toda su vida; un único hueso que conforma la mandíbula y se articula con el escamoso en el cráneo; el corazón dividido en cuatro cavidades; una cadena ósea en el oído medio compuesta por martillo, yunque y estribo; un diafragma muscular que separa las cavidades torácica y abdominal; lóbulos cerebrales bien diferenciados y corteza cerebral desarrollada; fertilización interna; los sexos separados y determinados en el caso de los machos por la hombre es capaz de consumir leche materna más allá del primer año de vida. Existen además culturas en las que la leche de hembras de especies diferentes a la del hombre mismo forma parte de su dieta básica incluso en la edad adulta (5). Y, más allá de entender que por el hecho de ser mamífero, el hombre consuma leche, la pregunta que surge es por qué lo hace durante tanto tiempo, qué razones tiene para hacerlo y cómo puede su organismo mantener la capacidad de aprovechar el contenido de nutrientes de ese producto. El objetivo de esta revisión es tratar de entender la trascendencia de la lactancia en las diferentes subclases de mamíferos, el significado que este proceso tiene para el hombre y cómo ha hecho este para proveerse de la leche de diferentes animales desde que tuvo noción de la importancia de tal producto en su dieta.

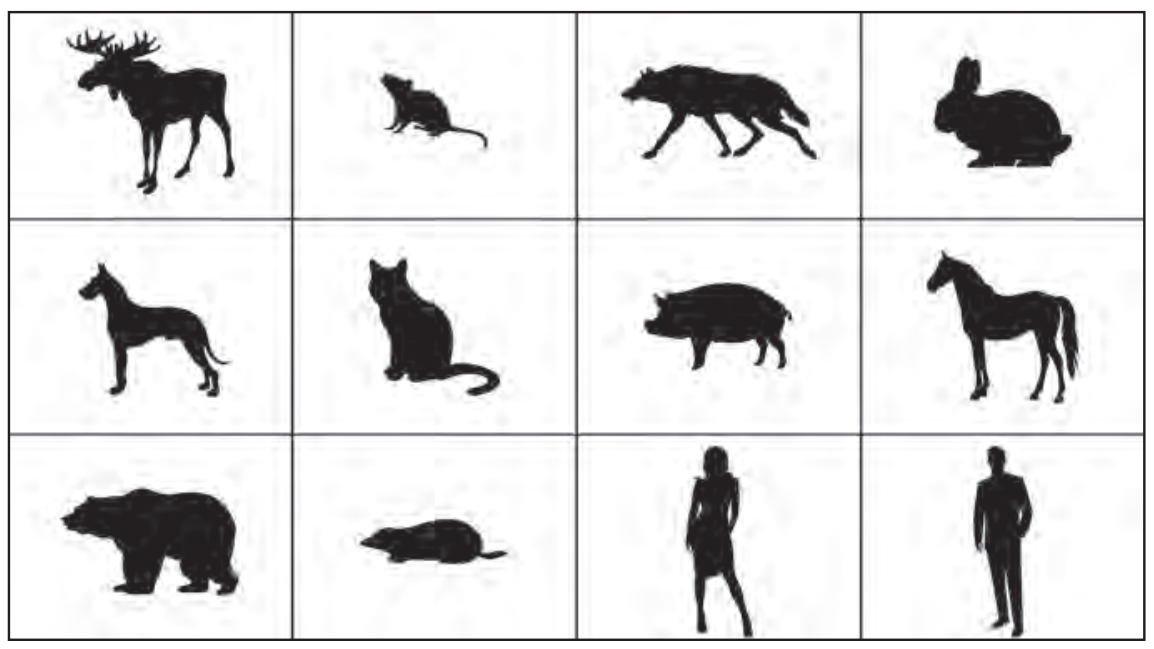

Figura $\mathrm{N}^{\circ}$ 1: Algunas siluetas de mamíferos. Izquierda a derecha, línea superior: alce, ratón, lobo, liebre; línea media: perro, gato, cerdo, caballo; línea inferior: oso, topo, mujer, hombre.

Fuente: http://es.vecteezy.com

presencia de los cromosomas $X Y Y$, cuando se trata de hembras, con dos cromosomas $X(1,2,3)$.

La peculiaridad que se toma como firma para clasificar a un individuo dentro del grupo de los mamíferos es la lactancia, es decir, el hecho de que las hembras alimentan a sus crías con la leche de sus mamas.

La lactancia protege, alimenta y contribuye a asegurar la supervivencia de las crías de cada especie y, posiblemente, se le puede considerar como el fenómeno que explica el hecho de que los mamíferos hayan sido capaces de ocupar una gran diversidad de hábitats en el planeta pues asegura la alimentación de los recién nacidos hasta que son capaces de alimentarse de otros productos de la naturaleza (4).

A diferencia de la mayoría de los mamíferos, el

\section{Glándulas mamarias}

Las glándulas mamarias o mamas son estructuras anatómicas exclusivas de los mamíferos que se derivan de glándulas sudoríparas modificadas que han adquirido un gran desarrollo y aparecen tanto en machos como en hembras pero es en estas donde se desarrollan totalmente y son capaces de secretar leche para alimentar a las crías (2).

Las mamas se originan durante el desarrollo intrauterino como engrosamientos ectodérmicos a manera de banda en la epidermis; esa banda es Ilamada línea mamaria, línea láctea o pliegue mamario y se extiende a ambos lados del cuerpo desde la base de la extremidad superior hasta la región de la extremidad inferior o región inguinal (1). En su estructura participan tres tejidos: el glandular, el 
adiposo y el cutáneo y están formadas por numerosos túbulos llamados conductos galactóforos que son en los que se vierte la leche secretada. Durante la vida embrionaria los conductos galactóforos desembocan en un pequeño hundimiento epitelial que, después y por proliferación del mesénquima subyacente, se convierte en el pezón $(1,6)$.

La cantidad, disposición y tamaño de las glándulas mamarias difiere entre las distintas especies de mamíferos y generalmente está en función de cuántas crías nacen en cada parto (2). En general se presentan en pares, dos en la cabra, la oveja, la yegua y el elefante así como en la mayoría de los primates. Otros ejemplos son la vaca con cuatro glándulas, ocho a diez en el perro, doce en la rata y 16 en los cerdos. Su disposición es bilateral, simétrica y paralela a la línea media en la pared ventral del tronco y pueden ser anteriores o torácicas (como en primates), intermedias - abdominales (como en los gatos), posteriores o inguinales (como en ovinos, bovinos y caprinos) o una combinación entre abdominales e inguinales (como en cerdos y perros) $(1,7)$.

\section{Los mamíferos según estrategia de reproducción y relación con la lactancia}

De acuerdo con su modo de reproducción, los mamíferos se dividen en tres subclases: 1) Prototheria, que incluyen al orden monotremas, organismos con reproducción ovípara cuyo registro fósil se estima aproximadamente de 166 a 220 millones de años; 2) Metatheria y 3) Eutheria, ambos que paren crías vivas y engloban a los marsupiales y los placentarios, respectivamente. Datan de hace unos 160 millones de años y la diferencia entre los dos grupos de organismos es que los marsupiales tienen un corto período en el útero materno y completan su crecimiento prendidos de las glándulas mamarias localizadas en el interior del marsupio de su madre; mientras que los placentarios presentan un largo período de gestación in útero, donde son alimentados a través de una placenta alantoica que también asegura la respiración del embrión lo que permite un mayor desarrollo de las crías $(8,9)$.

Además de las diferencias en el proceso de gestación, las tres subclases presentan particularidades en el proceso de lactancia de sus crías. Las glándulas mamarias de los monotremas se sitúan en el abdomen en estructuras llamadas campos lácteos que se han tomado como areolas, pero no presentan un pezón. Luego de la eclosión de los huevos, las crías toman la leche directamente de esos parches en el vientre de su madre y su alimentación y desarrollo dependen de ella completamente durante un período relativamente mayor al de la gestación e incubación de los huevos, pues el primero es de aproximadamente 10 días mientras que el segundo puede llegar a los cuatro meses $(3,8)$.

Los metaterios se caracterizan por poseer una bolsa, saco o marsupio que contiene a las mamas. Teniendo como referencia el trabajo de Trott et al. (2003), el período de lactancia de estos organismos se puede dividir en cuatro fases. La fase 1 corresponde a la gestación cuyo proceso es de cerca de 26 días tiempo en el que las cuatro glándulas mamarías de la hembra preñada se preparan para la lactancia y producen calostro.

Luego de la gestación, la cría recién nacida está muy poco desarrollada, con la piel desnuda, ojos y oídos embrionarios pero el olfato, la boca y los sistemas digestivo y respiratorio aptos para sobrevivir y, así, se arrastra sobre el cuerpo de su madre hasta la bolsa; cuando llega al borde, se deja caer dentro de ella, se prende de una de las mamas y comienza a lactar. A esta fase se conoce como 2A, dura entre 100 y 125 días y se caracteriza porque la cría está permanentemente pegada a la mama a la que llegó, mientras que las otras tres glándulas mamarías regresan a un estado de poco desarrollo.

Hacia el final de la fase 2A, la cría se separa de la glándula mamaría pero permanece dentro del marsupio hasta aproximadamente el día 200, fase conocida como $2 \mathrm{~B}$ y que se caracteriza por frecuentes pero intermitentes succiones de leche. La cuarta fase de esta secuencia, llamada fase 3, va de los 200 a los 350 días. Durante este período, la cría sale de la bolsa para comer pasto pero regresa al saco a mamar vigorosamente pero a intervalos menos frecuentes.

En total, el período de lactancia de los marsupiales es de 300 a 350 días, por lo que, aunque la cría deje el saco alrededor del día 250 y haya iniciado el cambio en su alimentación, regresará a la bolsa hasta que tal período sea completo. La leche secretada durante las fases $2 \mathrm{~A}$ y $2 \mathrm{~B}$ tiene bajos niveles de grasas y proteínas pero altos los de hidratos de carbono o glúcidos. En la transición hacia la fase 3, la composición de la leche cambia marcadamente, su producción se incrementa de manera significativa, la concentración de glúcidos baja y la de proteínas y grasas sube (10).

Los placentarios presentan una estrategia de reproducción lenta, por lo que están clasificados como estrategas K. Son individuos de especies con un potencial biótico bajo, sus tasas de natalidad y mortalidad son bajas, tienen pocas crías pero bien cuidadas, su población no fluctúa mucho en torno al valor $\mathrm{K} \circ$ incluso, por debajo de este, que está definido como el máximo número de individuos de una población que se puede mantener en condiciones ambientales determinadas. Esto asegura a los individuos más recursos de los que llegan a consumir. Son especies de ambientes estables, de ecosistemas 
maduros ecológicamente, de gran tamaño, de vida media larga y edad reproductiva tardía (7).

En cuanto a su presencia en la Tierra, el fósil de mamífero placentario más antiguo encontrado tiene aproximadamente 125 millones de años y fue hallado en el noreste de China (11). El origen de este grupo de organismos fue un evento importante en la historia evolutiva de los mamíferos, representan más del $90 \%$ de todos estos seres vivos y actualmente se conocen más de 5100 especies entre las que está la del hombre mismo (12).

En los placentarios, la lactancia se desarrolla durante períodos variables y se sugieren aquellos en los que las crías triplican o cuadruplican su peso de nacimiento. Por ejemplo, en conejos es de 28 a 35 días y en cabras va de 192 a 233 días $(13,14)$. En los búfalos es de 210 días (15) y en los cerdos puede llegar a los 56 días (16).

En los quirópteros existen características reproductoras diferenciales entre las distintas especies y familias. Por ejemplo, los murciélagos europeos que viven en las zonas de la Tierra que sufren inviernos rigurosos, ajustan sus ciclos reproductores -que requieren un gran gasto energético- a las épocas de máxima abundancia de alimento, esto es en la primavera y el verano. Durante estas dos estaciones pasan por las fases de gestación y lactancia de la nueva generación, debiendo además estar las crías suficientemente desarrolladas para cazar, orientarse en la oscuridad por medio de la ecolocalización y con reservas energéticas para afrontar el invierno (17).

Además, durante su vida adulta y dependiendo de la especie, los quirópteros presentan gran variabilidad de hábitos alimenticios que incluyen, escorpiones, arañas, néctar, polen y algunas partes de plantas y frutas, pequeños vertebrados y sangre tanto de mamíferos como de aves. Esto les crea diversos problemas en los tiempos de reproducción, la fase de lactancia y la transición de esta hacia el consumo de una dieta de adulto, por lo que no es sorprendente el hecho de que los murciélagos vampiros que se alimentan de sangre solo como adultos presenten un período de lactancia mucho más largo que individuos del mismo orden con otro tipo de dieta (18).

\section{La leche materna como primer alimento del hombre}

En el hombre, aunque existen numerosas opiniones al respecto, se recomienda la lactancia materna exclusiva durante seis meses y la lactancia materna continua con una alimentación segura, apropiada y adecuada (19). En este caso, sin embargo, el período de consumo de leche se prolonga más allá de los primeros años de vida y existen culturas en las que es parte de la dieta básica incluso en los adultos, aunque, cabe aclarar que la leche que se consume después del período inicial de la vida proviene de hembras de especies diferentes a la del hombre como la vaca, la cabra, la oveja, la camella, entre otras (5).

Debido a esto la industria lechera tiene gran relevancia y se ha reportado que el consumo per cápita de leche y productos lácteos es mayor en los países desarrollados, aunque la diferencia con muchos países en vías de desarrollo se está reduciendo. De hecho, en estos últimos la demanda de ambos productos está creciendo como consecuencia del aumento de ingresos, el crecimiento demográfico, la urbanización y los cambios en los regímenes alimentarios (20).

Pero, ¿̇cuál es la razón por la que el hombre es capaz de consumir leche más allá de su primer año de vida?, Idealmente durante la primera etapa de vida de un ser humano, la leche materna es su único alimento. Considerada como la primera vacuna, esta leche le proporciona los elementos necesarios para fortalecer sus sistemas digestivo e inmune porque contiene gran cantidad de componentes inmunológicos tanto humorales como celulares pues alrededor de la mitad de los anticuerpos que produce el organismo humano son del tipo A, esto es, la inmunoglobulina predominante en las secreciones exocrinas que protege las mucosas es la inmunoglobulina A secretora o $\lg A$. Ello explica el concepto de primera vacuna de la leche materna pues es una secreción que lleva anticuerpos contra todos los antígenos a los que la mujer que amamanta ha sido expuesta. $Y$ contiene, además de $\lg A s$, las inmunoglobulinas $\lg M$, $\lg G, \lg D$ e IgE así como componentes con actividad antiviral, antibacteriana y antiinflamatoria $(21,22)$.

Uno de esos componentes es la lactoferrina, molécula que favorece la absorción del hierro y es un factor de crecimiento y proliferación de la mucosa intestinal que ayuda en la incorporación de la timidina en el $A D N$, es inmunomodulante y anticarcinogénica. La función bacteriostática de la lactoferrina se debe a su capacidad para ligar iones Fe pues con ello priva de un nutriente esencial a las bacterias e inhibe su crecimiento (23).

La proteína sérica predominante en la leche humana es la $\alpha$-lactoalbúmina, una subunidad reguladora (subunidad B) de la enzima lactosa sintetasa, que en el organismo de la madre es una enzima crítica para el control de la lactancia y la secreción de leche además de ser una fuente de aminoácidos esenciales como el triptófano y la cisteína; $y$, una vez que se digiere a nivel intestinal libera péptidos con actividad antimicrobiana, inmunomoduladora y opiode (23).

Elementos antiinflamatorios de la leche materna son antioxidantes como las vitaminas A, C y E (23). Mientras que moléculas bioactivas como factores de crecimiento, 
citocinas y hormonas promueven el crecimiento $y$ maduración intestinal en el bebé y tienen efectos inmunomoduladores (24). Entre las hormonas que se le han encontrado están isómeros de la prolactina, leptina, estradiol, hormona adenocortocotropa, hormona estimulante de la tiroides, hormona del crecimiento, oxitocina, tiroxina, cortisol e insulina detectando además que la concentración de cada una varía, disminuyendo en general, durante un período de 180 días, tiempo estimado para la lactancia (25).

Pero la leche de origen humano no se produce ni se distribuye a escala industrial $y$, de hecho, la leche que consume la gente proviene de especies diferentes a la suya. Es por ello que vale preguntarnos: ¿̇cómo y desde cuándo llegó el hombre a abastecerse de la leche de otros mamíferos para obtener cantidades suficientes y así proveer a la población consumidora de este alimento?

\section{Domesticación de ganado para la obtención de leche}

Hace 11 mil años aproximadamente, en el período Neolítico el hombre inició la domesticación del ganado, propuesta según estudios arqueozoológicos, en los bosques y pantanos de la cuenca del río Éufrates, en la zona que hoy ocupa Irak. El hombre de esa época migró hacia Europa, hace cerca de 8400 años, llevando con él a los animales que había comenzado a cultivar y hace 6500 años, cuando se estableció en el centro de ese continente, basó su economía en la agricultura y en la explotación de ganado de diversas especies.

Los restos arqueológicos sugieren que fueron las ovejas y las cabras los primeros animales que se domesticaron, casi mil años antes que los bóvidos, animales más grandes y agresivos. En un principio, la cría de estos animales tenía por objeto beneficiarse con su carne y su piel pero, el descubrimiento del proceso de ordeña, significó un gran avance para el hombre pues de esa manera no tenía que sacrificar al animal para obtener un alimento altamente nutritivo y rico en proteínas (26).

En el transcurso de la historia, de alrededor de 148 especies no carnívoras solamente 15 han sido domesticadas. Trece de esas especies son originarias de Europa y Asia, mientras que solo dos tuvieron su origen en América del Sur. Únicamente seis de esas especies se han expandido a todos los continentes y conforman los ganados bovino, ovino, caprino, porcino, equino y el grupo conformado por los burros. Las otras nueve especies (dromedarios, camellos, llamas, alpacas, renos, búfalos, yaks, las vacas de Bali y el visón indio) son importantes en áreas limitadas del planeta (27).
La domesticación de animales se ha considerado realizada en aquellas especies que han logrado reproducirse en cautiverio y modificarse a partir de sus ancestros salvajes para favorecer las necesidades del ser humano. Esto implicó una asociación inicial con el nacimiento de crías en libertad; el comportamiento animal tal como la pérdida de agresión hacia los humanos; un instinto gregario y jerárquico en donde el hombre se acepta como líder; el confinamiento, en donde se procura cuidado y protección contra depredadores; la alimentación, con una dieta que pueda ser aportada fácilmente (por lo que es más fácil domesticar organismos herbívoros que carnívoros); el confinamiento con el nacimiento de crías en cautiverio con intervalos de reproducción relativamente cortos y la selección y mejoramiento de las razas $(27,28)$.

De los ganados mencionados, el bovino o vacuno ha llegado a convertirse en la especie doméstica más numerosa y económicamente más importante del mundo. Las ventajas que presenta este ganado en la producción de leche son su facilidad de ordeño por el tamaño de la ubre de las hembras así como su gran capacidad de producción y almacenamiento de leche.

De hecho, se estima que las vacas aportan el $83 \%$ de la producción de leche mundial. Otros animales lecheros menos comunes son los búfalos, las cabras, las ovejas y los camellos, que aportan el $13 \%, 2 \%$, 1 $\%$ y $0,3 \%$, respectivamente. La parte restante de este porcentaje procede de especies como los equinos y los yaks. En los tres últimos decenios, la producción lechera mundial ha aumentado en más del $50 \%$, pasando de 482 millones de toneladas en 1982 a 754 millones de toneladas en 2012 (29).

En el ámbito mundial, se ha calculado la existencia de aproximadamente 1355 millones de cabezas de ganado vacuno, repartidas en la actualidad en unas 990 razas y se estima que, desde su establecimiento como ganado domesticado y sobre todo en los últimos siglos, 209 razas se han extinguido debido a las prácticas de explotación (30).

Todos los miembros del ganado doméstico taurino y cebú actuales proceden del uro Bos primigenius. Estudios arqueozoológicos realizados en yacimientos de Oriente Próximo y sur de Asia han establecido dos eventos de domesticación de bovinos a partir de dos poblaciones de uros: en el primer sitio el ganado taurino con Bos taurus y en el segundo el ganado cebú con Bos indicus. A lo largo del tiempo, estas dos subespecies han dado origen a razas de vacas lecheras como la Holstein (desarrollada inicialmente en las provincias del norte de Holanda) y la Jersey (originaria de la pequeña isla británica de Jersey), entre muchas otras $(26,30)$.

Los elementos clave que determinan el mantenimiento 
de las especies lecheras son los alimentos, el agua y el clima (29). En México, además de las dos razas mencionadas, se cultivan otras como: Pardo Suiza Americana, Ayrshire, Guernsey, Shorthorn Lechera, Montbeliarde, Normada y las escandinavas (Sueca, Norvega y Danesa). $Y$ se estima que, el inventario de ganado lechero hasta 2012, se mantenía en 2,4 millones de cabezas siendo los principales Estados de la República productores de leche Jalisco, Coahuila, Durango, Chihuahua y Veracruz (31).

\section{Composición de la leche de vaca}

La composición química de la leche varía según la raza de vaca que la produce. Pero, en general, está compuesta principalmente por agua, iones (sal, minerales y calcio), grasas, constituyendo aproximadamente del $3 \%$ al $4 \%$ del contenido sólido, proteínas con 3,5\%, siendo las más comunes y representativas la caseína- $\alpha_{\mathrm{s} 1}$, la caseína- $\beta$ y la

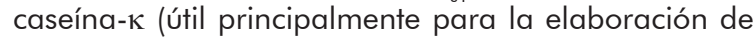
quesos) y un glúcido o azúcar que, en este caso, es la lactosa con $5 \%(20,32)$.

El glúcido lactosa se sintetiza en la glándula mamaria por un sistema enzimático en el que interviene la $\alpha$-lactoalbúmina. La lactosa es un disacárido formado por la unión de dos monosacáridos: una molécula de glucosa y otra de galactosa. Luego de que la leche es ingerida, la enzima llamada lactasa rompe o hidroliza el disacárido y sus componentes son absorbidos por el intestino delgado. Cuando no hay lactasa, la lactosa no puede ser absorbida por la mucosa del intestino y llega al colon en donde es fermentada por las bacterias presentes allí, causando dolor abdominal, flatulencias y diarrea (33).

En el metabolismo aeróbico, que es el que presentan todos los mamíferos, la primordial fuente de energía es proporcionada por los azúcares, glúcidos o hidratos de carbono siendo la glucosa el principal de ellos. De hecho, células como las del cerebro necesitan glucosa de manera constante por lo que es muy importante que haya siempre una determinada cantidad de este glúcido en la sangre. Esto explica el hecho de que el consumo de leche en los primeros años de vida de los mamíferos sea tan importante.

Teóricamente, el hombre, al igual que otras especies de mamíferos, puede digerir la leche solo durante la primera fase de su vida. Al nacer, en todos estos organismos el gen que codifica para la enzima lactasa se expresa y la proteína se produce en el borde de cepillo de las células que recubren las vellosidades intestinales. Luego, la expresión de la lactasa disminuye lo que naturalmente contribuiría al destete (34).

Sin embargo, se calcula que hace aproximadamente 7500 años, aquellos pobladores que se establecieron en el centro de Europa y que previamente señalamos, tuvieron una mutación en el promotor del gen de la lactasa que dio como resultado la expresión de la proteína también en los adultos. La mutación se extendió hacia el norte de Europa y Norteamérica, convirtiéndose en el fenotipo más frecuente. Simultáneamente, el hombre fortaleció el cultivo de ganado vacuno, ovino y caprino y conforme sus sociedades se desarrollaban implementó técnicas de conversión de la leche que obtenía de esos animales en productos que podía almacenar para consumirlos en las épocas de escasez. Esto proporcionó una ventaja evolutiva para el hombre pues le permitió la ingesta de leche o productos derivados de ella prácticamente a lo largo de toda su vida $(26,35)$.

En la actualidad se han planteado dos hipótesis para explicar la persistencia de la lactasa en el humano. La llamada hipótesis histórico-cultural plantea que el alelo que lleva la codificación de la lactasa se seleccionó en culturas con una larga historia en el cultivo de ganado productor de leche y en consecuencia en el consumo de la misma. Por otro lado, la hipótesis de causa reversa sostiene que el alelo pudo haber sido común en poblaciones humanas que adoptaron la práctica del cultivo de ganado lechero y el consumo de leche. Ambas teorías están sostenidas e influenciadas por el hecho de que las regiones donde aquellos hombres del Neolítico se establecieron presentaban climas áridos donde la leche era una fuente segura de agua; también, eran climas fríos que facilitaban el almacenamiento de los productos lácteos $y$, en latitudes más septentrionales, la concentración relativamente alta de vitamina $D$ de la leche ayudó a evitar enfermedades como el raquitismo pues la presencia de lactosa facilita la absorción de nutrientes de la leche tan importantes como el calcio $(26,33)$.

\section{Conservación de la leche}

La leche es casi estéril cuando es secretada por una ubre sana y posee inhibidores naturales como las enzimas lactoferrina y lactoperoxidasa que impiden el aumento significativo del número de bacterias (a temperatura ambiente) en las primeras tres o cuatro horas después del ordeño. Sin embargo, tiene un período de caducidad corto, principalmente si se conserva fresca ya que es un medio excelente para el crecimiento de patógenos bacterianos, que pueden provocar su deterioro y enfermedades en los consumidores, es por esto que exige una cuidadosa manipulación y debe ser distribuida tan pronto como sea posible después de su ordeño (20).

Dada su relevancia en la alimentación humana, la leche como muchos otros productos alimenticios, ha sido objeto de diferentes prácticas de conservación.

La historia reciente de los métodos de preservación 
de alimentos se remonta a 1791, cuando Nicolás Appert desarrolló un procedimiento que consistía en colocar alimentos en botellas de vidrio o recipientes de hojalata tapadas con corcho sujetos con alambre y sellados con cera o lacre que sometía a calentamiento en baño maría, durante un período de tiempo variable dependiendo de la naturaleza del alimento. En 1864, el método de Appert fue explicado científicamente y mejorado sensiblemente por Louis Pasteur, por lo que actualmente se conocen como pasteurización. Posteriormente, en 1907, Charles North aplicó con éxito el mismo método de Pasteur a la leche (36).

Además de la pasteurización, para la conservación de la leche también se emplean técnicas como la fermentación o el enfriamiento (que es el factor que más probablemente influya en la calidad de la leche cruda). La leche se transforma en productos fácilmente transportables, concentrados y de alto valor nutritivo, con un prolongado tiempo de conservación, como la mantequilla y el queso (20).

\section{CONCLUSIÓN}

La característica principal de los mamíferos es la lactancia. Considerada como primer alimento, la leche materna es de gran importancia para la sobrevivencia de las crías. El hombre es el único mamífero que puede consumir leche durante casi toda su vida. Dado que la leche humana no se produce a escala industrial, el hombre ha sido capaz de obtener leche de diferentes especies de mamíferos a los que ha domesticado. Además ha podido conservarla y transformarla para prolongar su consumo. Es por esto que en muchas partes del mundo y en el transcurso de la historia el ser humano ha calificado a la leche como un manjar $y$, de hecho, lo es.

\section{REFERENCIAS BIBLIOGRÁFICAS}

1. Hildebrand M. Anatomía y embriología de los vertebrados. México: Limusa; 1982.

2. Hill RW, Gordon AW, Anderson M. Fisiología Animal. Madrid: Médica Panamericana; 2006.

3. Padilla-Álvarez F, Cuesta-López AE. Clase mamíferos. Diversificación y adaptaciones. Sinopsis taxonómica de la clase mamíferos (Mammalia). En: Zoología Aplicada. Madrid: Díaz de Santos; 2003, p. 415-468.

4. Muñoz Cáceres H. Lactancia natural. En: Nazer JH, Ramírez RF. Neonatología. Santiago de Chile: Universitaria; 2003. p. 191-201.

5. Ojeda-Atxiaga M, Pérez-Elortondo FJ. Alimentos de origen animal. Leche y productos lácteos. En: Otero PP. Base de la alimentación humana. La
Coruña: Netbiblo; 2008

6. Secretaría de Salud. Compendio de anatomía patológica de la glándula mamaria. México D.F.: Salud; 2002.

7. Fanjul ML, Hiriart M. Biología funcional de los animales. Una fisiología comparada metabólica y ambiental. $2^{\underline{a}}$ ed. México D.F.: Siglo XXI; 2008.

8. Kuruppath S, Bisana S, Sharp J, Lefreve C, Kumar S, Nicholas K. Monotremes and marsupials: comparative models to beter understand the funcion of milk. J Biosci. 2012; 37(4): 581-588.

9. Enjapoori AK, Grant T, Nicol S, Lefevre C, Nicholas $\mathrm{K}$, Sharp J. Monotreme lactation protein is highly expressed in monotreme milk and provides antimicrobial protection. Genome Biol Evol. 2014; 6(10): 2754-2773.

10. Trott J, Simpson K, Moyle R, Hearn C, Shawn G, Nicholas $K$, et al. Maternal regulation of milk composition, milk production, and pouch young development during lactation in the Tammar Wallaby (Macropus eugenii). Biol Reprod. 2003; 68: 929-936.

11. Qiang J, Luo Z, Yuan C, Wible J, Zhang J, Georgi J. The earliest known eutherian mammal. Nature. 2002; 416: 816-822.

12. Campbell A, Reece JB. Biología. 7ํa ed. Madrid: Panamericana; 2007.

13. Dickinson L, Gamarra I, Salvador A, Monasterio L. Producción de leche y duración de la lactancia en cabras mestizas de la raza canaria en Venezuela. Archivos de Zootecnia. 2008; 57(217): 63-66.

14. Bidot-Fernández A. Producción de leche de cabra y duración de la lactancia de los genotipos Nubia, Saanen y Toggenburg en condiciones de pastoreo restringido y suplemento con concentrado. Abanico Veterinario. 2013; 3(1): 30-35.

15. Almaguer-Pérez Y. El búfalo, una opción de la ganadería. REDVET. Revista electrónica de veterinaria. 2007; VIII(8): 1-23.

16. Actualidad Porcina [Internet]. Lima: Equipo Periodístico Actualidad Porcina; 2013 octubre [citado el 09 de mayo de 2015]. Manejo de cerdas en el periodo de lactancia. [aprox. 2 pantallas]. Disponible en: http://www.actualidadporcina. com/articulos/manejo-de-cerdas-en-el-periodode-lactancia.html

17. Balmori A. La reproducción en los quirópteros. Galemys Spanish Journal of Mammalogy. 1999; $11(2)$ : 17-34.

18. Evarts J, Rasweiler J, Behringer R, Hennighausen $L$, Robinson G. A morphological and immunohistochemical comparison of mammary tissues from the short-tailed fruit bat (Carollia perspicillata) and the mouse. Biol Reprod. 2004; 70: 1573-1579.

19. Sguassero Y. Duración óptima de la lactancia materna exclusiva. Comentario de la BSR. La Biblioteca de Salud Reproductiva de la OMS. Ginebra: OMS; 2008. 
20. FAO [Internet]. Roma: FAO; 2010 septiembre [citado el 09 de mayo de 2015]. La producción láctea a pequeña escala [aprox. 2 pantallas]. Disponible en: http://www.fao.org/news/story/es/ item/45796/icode/

21. Riverón R. Valor inmunológico de la leche materna. Rev Cubana Pediatr [Internet]. 1995 agosto [citado el 04 de agosto de 2015]; 67(2): [aprox. 2 pantallas]. Disponible en: http://scielo. sld.cu/scielo.php? script=sci_arttext\&pid $=$ S0034$75311995000200006 \&$ lng $=$ es

22. Gavilanes P, Manjarrez H, Cravioto A. Inmunoprotección por leche materna. Revista Mexicana de Pediatría. 2002; 69(3): 111-119.

23. Gómez G, Pérez C, Bernal C, Periago C, Ros B. Compuestos funcionales de la leche materna. Enfermería Global. 2009; 16: 1-14.

24. Manjarrez H, Gavilanes P. Leche materna: protección insustituible. Ciencia y Desarrollo. 2009; 35(237): 8-15.

25. Ilcol Y, Hizli Z, Ozkan T. Leptin concentration in breast milk and its relationship to duration of lactation and hormone status. Int Breastfeed J. 2006; 1(21): 1-9.

26. Curry A. The milk revolution. Nature. 2013; 500: 20-22.

27. FAO. The State of the World's Animal Genetic Resources for Food and Agriculture. Roma: Rischkowsky B, Pilling D; 2007.

28. Bernis F. Zooarqueología de las faunas mixtas. En: Rutas de la Zooarqueología. Madrid: Complutense; 2001.

29. Organizaciones de las Naciones Unidas para la Alimentación la Agricultura [Internet] Roma: FAO;
2012 [citado el 10 de agosto de 2015]. Producción lechera [aprox. 2 pantallas]. Disponible en: http://www.fao.org/agriculture/dairy-gateway/ produccion-lechera/es/\#.V6OFXv197IU

30. Lira J. Revisión sobre la genética del origen del ganado vacuno y las aportaciones del ADN antiguo. MUNIBE. 2010; 61: 153-170.

31. Global Biotech Consulting Group [Internet]. México: GBC; 2013 [citado el 10 de agosto de 2015]. La industria ganadera en México [aprox. 2 pantallas]. Disponible en: http://www.gbcbiotech. com/bovinos/bovinos.html

32. Baró-Rodríguez L, Lara-Villoslada F, Corral-Román E. Leche y derivados lácteos. En: Gil-Hernández A, Ruiz-López MD. Tratado de Nutrición. Tomo II. Composición y calidad nutritiva de los alimentos. $2^{\text {a }}$ ed. Madrid: Médica Panamericana; 2010.

33. Kruttli A, Bouwman A, Akgu G, Della Casa P, Ruhli F, Warinner C. Ancient DNA Analysis Reveals High Frequency of European Lactase Persistence Allele (T-13910) in Medieval Central Europe. PLoS ONE. 2014; 9(1): 1-8.

34. Sierra-Salinas C, Navas-López VM, MaldonadoLozano J. Nutrición en la diarrea aguda y en los síndromes de malabsorción en la infancia. En: GilHernández A, et al. Tratado de Nutrición. Tomo IV. Nutrición Clínica. Madrid: Médica Panamericana; 2010.

35. Misselwitz B. Lactose intolerance: New Insights due to Blinded Testing? Digestion. 2014; 90: 72-73.

36. Barón A. Historia de la conservación de los alimentos. En: Salas J, García P, Sánchez JM. La alimentación y la nutrición a través de la historia. Barcelona: Glosa; 2005. 